\title{
Analysis of prolene hernia system in the management of uncomplicated inguinal hernia in comparison to lichtenstein mesh repair
}

\author{
Santosh M.P', Niyaz Mohamed $S^{2}$ \\ ${ }^{1}$ Dr. Santosh M.P, Assistant Professor, Department of General Surgery, Raja Rajeswari Medical College \& Hospital, \\ Bangalore, India, ${ }^{2}$ Dr Niyaz Mohamed S, Consultant surgeon, Columbia Asia hospital, Yeshwanthpur, Bangalore, India.
}

Address for Correspondence: Dr. Santosh MP, Assistant Professor, Department of General Surgery, Raja Rajeswari Medical College \& Hospital, Bangalore, India. Email: dr.santoshmp@gmail.com

\begin{abstract}
Introduction: Worldwide, inguinal hernia repair is probably the most commonly performed general surgical procedure. Hence, a slight refinement of surgical repair of inguinal hernia would mean a substantial benefit to the patient. Aim: The study aims to compare the prolene hernia system (PHS) and Lichtenstein mesh repair (LMR) in the management of uncomplicated inguinal hernia. Materials and Methods: This was a prospective, comparative study done at a tertiary care hospital over a period of 18 months. Results: Mean age of the patients in the study was 45.43 years. $98.2 \%$ of patients were male and $69.2 \%$ of hernia was right sided. The duration of surgery (36.48 minutes vs. 47.26 minutes) and duration of hospital stay (6.68 days vs. 7.61 days) was considerably lesser in PHS group when compared to LMR group and was statistically significant. Post-operative pain in PHS group was also lesser, though not of statistical significance. There was no difference between two groups in the rates of seroma formation, wound infection, scrotal pain/ swelling, chronic groin pain, presence of foreign body sensation and recurrence. Conclusion: Prolene hernia system is comparable to Lichtenstein mesh repair in the management of uncomplicated inguinal hernia but not good enough to replace it.
\end{abstract}

Key words- Inguinal hernia, Prolene hernia system, Lichtenstein mesh repair

\section{Introduction}

The most commonly performed general surgical procedure had to be inguinal hernia repair [1]. The surgical treatment of inguinal hernia has taken several important steps forward in the past 125 years. However, the fact that we still employ a wide variety of techniques to operate on inguinal hernia clearly shows that the road to a perfect operation is still ahead us.

There are three important landmarks in the history of repair of inguinal hernia [2].

1. Tissuerepair - Eduardo Bassini, 1888

2. Onlay mesh (tension-free repair) - Irving Lichtenstein, 1984

3. Laparoscopic repair - Ger, Shultz, Corbitt etc, 1990.

In order to achieve a radical cure of hernia it is absolutely essential to restore those conditions in the area of the hernial orifice, which exist under normal conditions [2]. Eduardo Bassini believed complete reconstruction of the

Manuscript Received: $30^{\text {th }}$ September 2017

Reviewed: $9^{\text {th }}$ October 2017

Author Corrected: $18^{\text {th }}$ October 201

Accepted for Publication: $25^{\text {th }}$ October 2017 anatomy of the inguinal canal can lead to a full recovery from inguinal hernia. His achievement is even more impressive if we realize that all subsequent methods of inguinal hernia surgery until introduction of artificial materials were in fact variants of Bassini concept [3].

In 1984, better understanding of inguinal hernia as a "metabolic disease" andhigher rates of recurrence due to tension along the suture lines after tissue repair, popularized the routine use of mesh, coining the term "tension-free", hernioplasty $[4,5,6]$. It has been more than 30 years after the introduction of the Lichtenstein tensionfree hernioplasty in 1984 . The procedure has been thoroughly scrutinised in large series and by generations of surgeons and has a universal acceptance. It is considered the gold standard of inguinal hernia repairs by the American College of Surgeons [7]. Procedure can be easily taught to the surgical trainees and its effectiveness (a recurrence and complication rate of approximately $1 \%$ in the hands of nonexperts) is virtually the same asits reported efficacy (a recurrence and complication rate of $1 \%$ or less in the hands of experts) $[8,9]$. 


\section{Original Research Article}

The standing of Lichtenstein mesh repair (referred to as LMR henceforth) as the reference technique was only called to question when the laparoscopic technique burst into the scene back in the 90s [10].

The initial enthusiasm for the endoscopic hernia repair was understandable, as placement of a single mesh in pre peritoneal space covering the entire myo pectineal orifice (MPO) seemed a one-step solution for all groin hernias [11]. However, it became clear that although these techniques have some important advantages for patients, in no way can they be considered the ideal operation for every patient. Laparoscopic hernia repair has a steep learning curve, difficult to be taught to the surgical trainees and has its fair share of dangerous complications [12]. Thus, laparoscopic hernia repair, while still popular in some centres, coexists peacefully with traditional open techniques of hernia repair [2]. In 1999 Arthur Gilbert described a technique that allows placing a mesh both in "onlay" and "sublay" position. His Prolene Hernia System (henceforth referred to as PHS) consisted a sophisticated mesh built from two meshes of different shape connected with a small tube. Thus, posterior wall of the inguinal canal was reinforced both from preperitoneal site (covering MPO, like laparoscopic repair) and from the "onlay" position (like LMR) with minimal fixation [Figure 1,2] [13,14]. Hence the prolene hernia system offered the advantage of laparoscopic repair (as it covers entire MPO) done through a familiar anterior approach and minimal mesh fixation meant lesser chances of chronic groin pain.

Though the PHS (device covering three spaces: preperitonealspace, deep inguinal ring/medial defect, posterior wall of the inguinal canal) seemed attractive on many fronts, it had to offer substantial advantages to replace the simple and effective Lichtenstein mesh repair. We conducted a prospective study comparing the prolene hernia system and Lichtenstein mesh repair in the management of uncomplicated inguinal hernia.

\section{Materials and Methods}

Study design: This was a prospective, comparative study done at a tertiary care hospital over a period of 18 months.

Study sample: A total of 56 patients were included in the study after they met the inclusion criteria. They were assigned to two groups (LMR and PHS) on odd/even basis. The first patient and all odd numbered patients $\left(3^{\text {rd }}, 5^{\text {th }}\right.$ and so on) were assigned to the LMR group. The second patient and all even numbered patients $\left(4^{\text {th }}, 6^{\text {th }}\right.$ and so on) were assigned to the PHS group. There were a total of 28 patients in each group.

\section{Inclusion criteria}

1. Patients admitted to department of general surgery with uncomplicated inguinal hernia (both direct and indirect) were included in the study.

2. Patients 18 years and above.

\section{Exclusion criteria}

1. Paediatric inguinal hernia.

2. Patients admitted with complicated inguinal hernia (irreducible, incarcerated and strangulated) were excluded from the study.

Sample collection: Patient symptomatology, risk factors for hernia and co morbid conditions were noted. Patients were investigated and prepared as per the standard hospital protocol. All patients underwent surgery under regional anaesthesia. The duration of surgery (calculated as the time from skin incision till closure of the wound), post-operative complications (seroma, hematoma, wound infection, groin pain) and the duration of hospital stay were recorded. Post-operative groin pain was assessed for all patients on days 1,7, 14 both at rest and on walking. VAS (visual analogue scale) [15] score was used to asses groin pain and was classified as follows [Table-1].

Table-1: Pain score according to Visual Analogue Scale.

\begin{tabular}{|c|c|}
\hline Category & Score \\
\hline None & 0 \\
\hline Mild & $1,2,3$ \\
\hline Moderate & $4,5,6$ \\
\hline Severe & $7,8,9,10$ \\
\hline
\end{tabular}


Patients were followed up for a minimum of 6 months (either telephonically or in person) to check for recurrence, chronic groin pain and presence of foreign body sensation. All the data collected was compared between two groups.

Statistical Methods: Descriptive statistical analysis has been carried out in the present study. Results on continuous measurements are presented on Mean +/- SD (Min-Max) and results on categorical measurements are presented in Number (\%). Significance is assessed at $5 \%$ level of significance., Student $t$ test has been used to find the significance of study parameters on continuous scale between two groups Inter group analysis). Chi-square/ 2x2, 2x3, 2x4 Fisher Exact test has been used to find the significance of study parameters on categorical scale between two or more groups. $95 \%$ Confidence Interval has been computed to find the significant features.

Significant figures:

+ Suggestive significance (P value: $0.05<\mathrm{P}<0.10$ )

* Moderately significant ( $\mathrm{P}$ value: $0.01<\mathrm{P}</=0.05$ )

** Strongly significant $(\mathrm{P}$ value: $\mathrm{P}</=0.01)$

Statistical software: The Statistical software namely SPSS 15.0, Stata 8.0, MedCalc 9.0.1 and Systat 11.0 were used for the analysis of the data and Microsoft word and Excel have been used to generate graphs, tables etc $[16,17,18]$.

\section{Results}

A total of 56 patients were included in the study after they met the inclusion criteria. They were assigned to LMR $(n=28)$ and PHS $(n=28)$ groups on odd/even basis.

Mean age of the patients in LMR group was 46.86 years and in PHS group it was 44 years. Mean age of patients in both groups were comparable $(\mathrm{P}=0.516)$. There was only one female patient.

The main complaint of the patients was swelling and discomfort in the groin $(41.4 \%, n=26) .25 \%$ of the patients presented only with the swelling in the groin $(\mathrm{n}=14)$.

Right sided hernia was more common in the study (69.2\%). Side involved is statistically similar in both the groups with $\mathrm{P}=0.771$.

Distribution of co-morbid conditions are statistically similar between two groups $(\mathrm{P}=0.179)$, even though co morbidities were more in Group LMR (28.6\%) when compared to Group PHS (17.9\%). COPD was the most common co morbidity seen in the study (16.1\%).

More than half of the patients in the study gave history of smoking. Smokers are more in Group LMR (67.9\%) when compared to $42.9 \%$ in Group PHS with $\mathrm{P}=0.060$.

The duration of surgery was calculated from the time of skin incision to the time of closure. Mean duration of surgery was significantly lesser in the PHS group (36.48 mins) compared to LMR group (47.26 mins), $\mathrm{P}<0.001$ [Table-2].

Table-2: Duration of surgery.

\begin{tabular}{|c|c|c|}
\hline Duration of surgery (in mins) & $\begin{array}{c}\text { Group LMR } \\
(\mathbf{n = 2 8})\end{array}$ & $\begin{array}{c}\text { Group PHS } \\
(\mathbf{n = 2 8})\end{array}$ \\
\hline Min - Max & $35-56$ & $23-50$ \\
\hline Mean+/-SD & $47.26+/-6.56$ & $36.48+/-8.33$ \\
\hline
\end{tabular}

After surgery patients were evaluated for post-operative groin pain using VAS score. The scoring was done on post op Days 1,7 and 14 (Day 1 being the day after surgery). Pain was assessed on rest and on walking. The percentage change in the nature of pain from day 1 till day 14 was noted.

The results were compared between the two groups. It was found that VAS scores on days 1,7,14 and at rest and on walking was statistically similar between the two groups [Tables-3a,3b, 4a, 4b]. 


\section{Original Research Article}

Table- 3a: Evaluation of postoperative pain with VAS score on resting.

\begin{tabular}{|c|c|c|c|c|c|c|c|c|c|}
\hline \multirow[t]{2}{*}{ VAS score } & \multicolumn{4}{|c|}{$\begin{array}{c}\text { Group LMR } \\
(n=28)\end{array}$} & \multicolumn{4}{|c|}{$\begin{array}{c}\text { Group PHS } \\
(n=28)\end{array}$} & $\begin{array}{c}P \\
\text { value }\end{array}$ \\
\hline & None & Mild & Mod & Severe & None & Mild & Mod & Severe & \\
\hline Day 1 & 0 & $\begin{array}{c}12 \\
(42.9 \%)\end{array}$ & $\begin{array}{c}14 \\
(50.0 \%)\end{array}$ & $\begin{array}{c}2 \\
(7.1 \%)\end{array}$ & 0 & $\begin{array}{c}15 \\
(53.5 \%)\end{array}$ & $\begin{array}{c}10 \\
(35.7 \%)\end{array}$ & $\begin{array}{c}3 \\
(10.7 \%)\end{array}$ & 0.614 \\
\hline Day 7 & $\begin{array}{c}8 \\
(28.6 \%)\end{array}$ & $\begin{array}{c}13 \\
(46.4 \%)\end{array}$ & $\begin{array}{c}6 \\
(21.4 \%)\end{array}$ & $\begin{array}{c}1 \\
(3.6 \%)\end{array}$ & $\begin{array}{c}10 \\
(35.7 \%)\end{array}$ & $\begin{array}{c}11 \\
(39.3 \%)\end{array}$ & $\begin{array}{c}5 \\
(17.9 \%)\end{array}$ & $\begin{array}{c}2 \\
(7.1 \%)\end{array}$ & 0.865 \\
\hline Day 14 & $\begin{array}{c}20 \\
(71.4 \%)\end{array}$ & $\begin{array}{c}6 \\
(21.4 \%)\end{array}$ & $\begin{array}{c}2 \\
(7.1 \%)\end{array}$ & 0 & $\begin{array}{c}23 \\
(82.1 \%)\end{array}$ & $\begin{array}{c}5 \\
(17.9 \%)\end{array}$ & 0 & 0 & 0.453 \\
\hline$\%$ change & $+71.4 \%$ & $-21.5 \%$ & $-42.8 \%$ & $-7.1 \%$ & $+82.1 \%$ & $-35.7 \%$ & $-35.7 \%$ & $-10.7 \%$ & - \\
\hline
\end{tabular}

By day $14,71.4 \%$ of patients in LMR group and $82.1 \%$ of patients in PHS had no pain at rest.

Table-3b: Evaluation of mean VAS score (Resting) in two groups of patients

\begin{tabular}{|c|c|c|c|}
\hline VAS score (Resting) & $\begin{array}{c}\text { Group LMR } \\
(\mathbf{n = 2 8})\end{array}$ & $\begin{array}{c}\text { Group PHS } \\
(\mathbf{n = 2 8})\end{array}$ & P value \\
\hline Day 1 & $4.25 \pm 2.08$ & $4.04 \pm 2.38$ & 0.721 \\
\hline Day 7 & $2.45 \pm 2.06$ & $2.32 \pm 2.25$ & 0.805 \\
\hline Day 14 & $0.82 \pm 1.57$ & $0.43 \pm 0.99$ & 0.269 \\
\hline
\end{tabular}

On days 1, 7 and 14, mean VAS score at rest was lesser in PHS group compared to LMR group, though not statistically significant.

Table-4a: Evaluation of postoperative pain with VAS score on walking.

\begin{tabular}{|c|c|c|c|c|c|c|c|c|c|}
\hline \multirow[t]{2}{*}{ VAS score } & \multicolumn{4}{|c|}{$\begin{array}{c}\text { Group LMR } \\
(\mathrm{n}=\mathbf{2 8})\end{array}$} & \multicolumn{4}{|c|}{$\begin{array}{c}\text { Group PHS } \\
(n=28)\end{array}$} & \multirow[t]{2}{*}{ P value } \\
\hline & None & Mild & Mod & Severe & None & Mild & Mod & Severe & \\
\hline Day 1 & 0 & $\begin{array}{c}6 \\
(21.4 \%)\end{array}$ & $\begin{array}{c}15 \\
(53.6 \%)\end{array}$ & $\begin{array}{c}7 \\
(25.0 \%)\end{array}$ & 0 & $\begin{array}{c}7 \\
(25.0 \%)\end{array}$ & $\begin{array}{c}17 \\
(60.7 \%)\end{array}$ & $\begin{array}{c}4 \\
(14.3 \%)\end{array}$ & 0.670 \\
\hline Day 7 & $\begin{array}{c}6 \\
(21.4 \%)\end{array}$ & $\begin{array}{c}13 \\
(46.4 \%)\end{array}$ & $\begin{array}{c}7 \\
(25.0 \%)\end{array}$ & $\begin{array}{c}2 \\
(7.1 \%)\end{array}$ & $\begin{array}{c}7 \\
(25.0 \%)\end{array}$ & $\begin{array}{c}15 \\
(53.6 \%)\end{array}$ & $\begin{array}{c}3 \\
(10.7 \%)\end{array}$ & $\begin{array}{c}3 \\
(10.7 \%)\end{array}$ & 0.620 \\
\hline Day 14 & $\begin{array}{c}18 \\
(64.3 \%)\end{array}$ & $\begin{array}{c}7 \\
(25.0 \%)\end{array}$ & $\begin{array}{c}2 \\
(7.1 \%)\end{array}$ & $\begin{array}{c}1 \\
(3.6 \%)\end{array}$ & $\begin{array}{c}21 \\
(75.0 \%)\end{array}$ & $\begin{array}{c}6 \\
(21.4 \%)\end{array}$ & $\begin{array}{c}1 \\
(3.6 \%)\end{array}$ & 0 & 0.722 \\
\hline$\%$ change & $+64.3 \%$ & $+3.6 \%$ & $-46.5 \%$ & $-21.4 \%$ & $+75.0 \%$ & $-3.6 \%$ & $-57.1 \%$ & $-14.3 \%$ & - \\
\hline
\end{tabular}

By day $14,64.3 \%$ of patients in LMR group and $75 \%$ of patients in PHS had no pain on walking.

Table-4b: Evaluation of mean VAS score (on Walking) in two groups of patients.

\begin{tabular}{|c|c|c|c|}
\hline VAS score (Walking) & $\begin{array}{c}\text { Group LMR } \\
(\mathbf{n = 2 8})\end{array}$ & $\begin{array}{c}\text { Group PHS } \\
(\mathbf{n = 2 8 )}\end{array}$ & P value \\
\hline Day 1 & $5.75 \pm 2.24$ & $5.36 \pm 2.09$ & 0.501 \\
\hline Day 7 & $2.79 \pm 2.52$ & $2.46 \pm 2.44$ & 0.629 \\
\hline Day 14 & $0.89 \pm 1.73$ & $0.39 \pm 0.88$ & 0.178 \\
\hline
\end{tabular}

Mean VAS score on walking was lesser in PHS group on days 1,7,14 when compared to LMR group.

Incidence of complications post operatively (hematoma, seroma, wound infection, scrotal swelling/pain) was similar in both the groups $(28.6 \%)$. Seroma formation $(10.7 \%)$ was the most common complication in the LMR group, while scrotal pain/swelling (14.3\%) was common in PHS group. Only one patient in LMR group had wound infection (3.6\%) [Table-5]. 
Original Research Article

Table-5: Comparison of incidence of complications in two groups of patients.

\begin{tabular}{|c|c|c|}
\hline Complications & $\begin{array}{c}\text { Group LMR } \\
(\mathbf{n = 2 8 )}\end{array}$ & $\begin{array}{c}\text { Group PHS } \\
(\mathbf{n}=\mathbf{2 8})\end{array}$ \\
\hline Absent & $20(71.4 \%)$ & $20(71.4 \%)$ \\
\hline Present & $8(28.6 \%)$ & $8(28.6 \%)$ \\
\hline Hematoma & $2(7.1 \%)$ & $1(3.6 \%)$ \\
\hline Scrotal swelling/Pain & $2(7.1 \%)$ & $4(14.3 \%)$ \\
\hline Seroma & $3(10.7 \%)$ & $3(10.7 \%)$ \\
\hline Wound infection & $1(3.6 \%)$ & 0 \\
\hline Inference & Presence of complications are statistically similar between two groups with $\mathrm{P}=1.000$ \\
\hline
\end{tabular}

The duration of hospital stay post operatively was lesser in the PHS group and it was significant statistically. Majority of the patients were discharged after 5 days in both the groups [Table-6].

Table-6: Comparison of duration of hospital stay in days.

\begin{tabular}{|c|c|c|}
\hline Hospital stay in days & $\begin{array}{l}\text { Group LMR } \\
\qquad(\mathrm{n}=\mathbf{2 8})\end{array}$ & $\begin{array}{l}\text { Group PHS } \\
(\mathbf{n}=\mathbf{2 8})\end{array}$ \\
\hline 1-2 days & 0 & 0 \\
\hline 3-4 days & 0 & 2 \\
\hline 5-7 days & 13 & 17 \\
\hline$>7$ days & 15 & 9 \\
\hline Mean \pm SD & $7.61 \pm 1.23$ & $6.68 \pm 1.39$ \\
\hline Inference & \multicolumn{2}{|c|}{$\begin{array}{l}\text { Duration of hospital stay is significantly less in PHS group (6.68 days vs. } 7.61 \\
\text { days) with } \mathrm{P}=0.011^{*}\end{array}$} \\
\hline
\end{tabular}

Patients were followed up 6 months after surgery to evaluate for chronic groin pain and presence of foreign body sensation. 3 patients in LMR group and 1 patient in PHS group had chronic groin pain. However this was not statistically significant $(\mathrm{P}=0.611)$ [Table-7].

Table-7: Comparison of incidence of Chronic Groin pain.

\begin{tabular}{|c|c|c|}
\hline Chronic Groin Pain & $\begin{array}{c}\text { Group LMR } \\
(\mathbf{n = 2 8 )}\end{array}$ & $\begin{array}{c}\text { Group PHS } \\
(\mathbf{n = 2 8 )}\end{array}$ \\
\hline Absent & $25(89.3 \%)$ & $27(96.4 \%)$ \\
\hline Present & $3(10.7 \%)$ & $1(3.6 \%)$ \\
\hline Inference & \multicolumn{2}{|c|}{$\begin{array}{c}\text { Incidence of Chronic Groin pain is statistically similar between two groups } \\
\text { with } \mathrm{P}=0.611\end{array}$} \\
\hline
\end{tabular}

Patients were enquired for the presence of foreign body sensation following surgery. There was no statistical difference between presence of foreign body sensation between two groups (10.7\% in LMR group and 14.3\% in PHS group).

\section{Discussion}

Worldwide, some 20 million hernia repairs are accomplished each year. The significance of these large numbers is that the small variations in practice patterns can have huge socioeconomic implications [19].

Mean age of the patients in the study was 45.43 years. In the study done by Matyja et al [20] the mean age of the patients was 46.7 years. In our study both the groups were age matched statistically with mean age of 46.86 years in LMR group and 44 years in PHS group. This is comparable to other studies [21, 22, 23].

All the patients in the current study were male (98.2\%) except for one female patient in the LMR group (1.8\%). Male predominance was also observed in other studies[20,23]. 


\section{Original Research Article}

Right sided inguinal hernia was common in our study (69.7\%). There were no cases of bilateral hernia in our study. Right sided inguinal hernia was common in other studies $[23,24,25]$.

Duration of surgery in our study was significantly lesser in the PHS group compared to the LMR group. This is probably due to lesser sutures needed to fix the bilayered device. Several studies did not find statistically significant difference between the two groups regarding the duration of surgery, however many opined PHS takes a longer time than LMR [21,22,23].

In our study post-operative pain was evaluated on days 1,7 and 14 both at rest and on walking using VAS score. Shankar \& Hiregoudar et al [23] evaluated for pain on days 1,3,8 and Karaca et al [21] on days 1,7,30. The incidence of moderate and severe pain decreased with time in both the groups. However, there was no statistically significant difference in pain between two groups, although few studies claimed less pain the PHS group (Badkur \& Garg) [22].

$28.6 \%$ of the patients in the study had complications. Post-operativeseroma (10.7\%) was common in LMR group andscrotal swelling/pain (14.3\%) was common inPHS group. In other studies, incidence of the seroma formation in post op period ranged from $0.6 \%$ to $11.8 \%$. None of the studies showed statistically significant difference between the two groups, comparable to our study $[20,22,23]$.

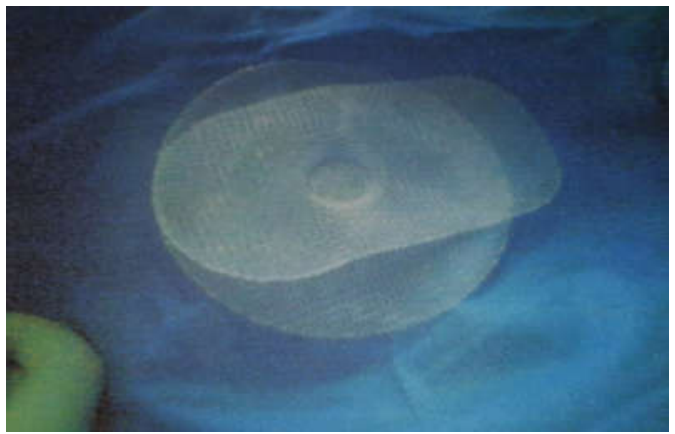

Figure 1: Prolene hernia system

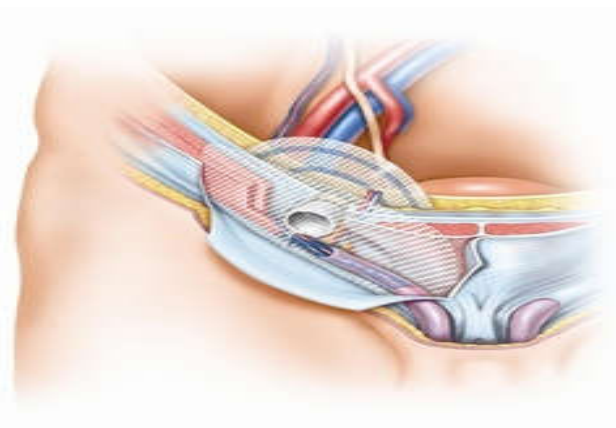

Figure 2: Area covered by prolene hernia system

Only one patient in our study had superficial wound infection (3.6\%) and it is comparable to other studies[20, 22, 23]. Karaca et al [21] reported no wound infections following surgery.

In our study, the mean duration of post-operative hospital stay for the LMR group is $7.61 \pm 1.23$ days, whereas for the PHS group is $6.68 \pm 1.39$ days and it was statistically significant. A study by Badkur \& Garg [22] also had similar findings -4.8 days in LMR group and 3.5 days in PHS group. Other studies did not report statistically significant difference in the duration of post-operative hospital stay between two groups $[21,23]$.

Now with recurrence rates after mesh repair for inguinal hernia are less than $1 \%$, chronic inguinodynia (chronic groin pain) following surgery is a challenge to the surgeons. $7.2 \%$ of patients in our study had chronic groin pain. Other studies reported incidence of chronic groin pain from $4.5 \%$ to $11 \%$ comparable to our study [22, 23, 26, 27].

The incidence of chronic groin pain was lesser in the PHS group when compared to the LMR group in our study. Similarly, majority of the studies showed lesser chronic groin pain in PHS group [20, 22, 23].

There were no recurrences noted in the study.

\section{Conclusion}

The Lichtenstein mesh repair has withstood the time and hence many evaluations, to become the gold standard for inguinal hernia repair. Any other open technique for inguinal hernia repair should offer substantial advantages to question the Lichtenstein mesh repair let alone replace it. Prolene hernia system offered that hope. PHS offered the theoretical advantage of prosthesis covering the entire MPO, thus eliminating possibility of future occurrence of femoral hernia also. In our study, we found that inguinal hernia was commonly seen in males and are more often right sided. PHS took a considerably lesser time of surgery compared to the standard Lichtenstein mesh 


\section{Original Research Article}

repair, probably owing to lesser/ no fixation of the mesh. Post-operative pain following PHS repair, was lesser when compared to Lichtenstein mesh repair. PHS did not differ from LMR in the incidence of other post-operative complications. Patients were discharged much earlier following PHS repair. On a slightly longer follow up the incidence of chronic groin pain, foreign body sensation and recurrences were comparable. The major limiting factor for PHS was the cost factor which is 5-7 times more compared to Lichtenstein mesh repair. To conclude, Lichtenstein mesh repair still continues to be the gold standard for inguinal hernia repair. PHS can be offered to patients especially if they can afford it.

What does this study add to existing knowledge? - The study reaffirms the superiority of a simple, cost effective Lichtenstein mesh repair for inguinal hernia repair. In a developing country like ours, prolene hernia system adds to the financial burden with very little added benefits and hence cannot be considered ideal for inguinal hernia repair.

\section{Author contribution:}

${ }^{1}$ Study conception and design, acquisition of data, analysis and interpretation of data, drafting of manuscript, critical revision

${ }^{2}$ analysis and interpretation of data, drafting of manuscript, critical revision.

Acknowledgement: Dr. K. P. Suresh, Scientist (Biostatistics), National Institute of Veterinary Epidemiology and Disease Informatics (NIVEDI), Bangalore- 560024, for reviewing the research methodology and statistical results of the study.

Conflict of interest: None declared.

Funding: Nil, Permission from IRB: Yes

\section{References}

1. Vironen J, Nieminen J, Eklund A, Paavolainen P. Randomized clinical trial of Lichtenstein patch or Prolene Hernia System for inguinal hernia repair. Br J Surg. 2006 Jan; 93 (1):33-9.

2. Pancholi, M., Sharma, P., \& Patel, G. R. Retrospective Study of Repair of Inguinal Hernia by Various Methods of Surgery, Comparing their Results and rate of Complications in the Teaching Institute of South Gujarat. Gujarat medical journal. 2012; 67(2):22-24.

3. Thomas AD, Rogers A. Edoardo Bassini and the Wound That Inspires. World J. Surg. 2004;28:1060-1062. DOI: https://doi.org/10.1007/s00268-004-7466-5.
4. Read RC. A review: the role of protease-antiprotease imbalance in the pathogenesis of herniation and abdominal aortic aneurism in certain smokers. Postgrad Gen Surg.1992; 4:161-5.

5. Rosch R, Klinge U, Si Z, Junge K, Klosterhalfen B, Schumpelick V. A role for the collagen I/III and MMP-1/13 genes in primary inguinal hernia? BMC Med Genet. 2002; 3:2. Epub 2002 Feb 19.

6. Wantz GE. Experience with the tension-free hernioplasty for primary inguinal hernias in men. J Am Coll Surg. 1996 Oct;183(4):351-6.

7. Fitzgibbons R.Management of an inguinal hernia: Conventional? Tension-free? Laparoscopic? or maybe no treatment at all. General Sessions of the American College of Surgeons.86th Annual Clinical Congress.2000.

8. Shulman AG, Amid PK, Lichtenstein IL. A survey of non-expert surgeons using the open tension-free mesh repair for primary inguinal hernias. Int Surg. 1995; 80: 35-36.

9. Kingsnorth AN, Bowley DMG, Porter C.A prospective study of 1000 hernias: results of the Plymouth Hernia Service. Ann R Coll Surg Engl.2003; 85(1):18-22.

10. Ger R, Monroe K, Duvivier R, Mishrick A. Management of indirect inguinal hernias by laparoscopic closure of the neck of the sac. Am J Surg 1990;159(4): 370-373. DOI: http://dx.doi.org/10.1016/S0002-9610(05) 81273-5.

11. Simons MP, Aufenacker T, Bay-Nielsen M, Bouillot JL, Campanelli G, Conze J, de Lange D, Fortelny R, Heikkinen T, Kingsnorth A, Kukleta J, Morales-Conde S, Nordin P, Schumpelick V, Smedberg S, Smietanski M, Weber G, Miserez M. European Hernia Society guidelines on the treatment of inguinal hernia in adult patients. Hernia. 2009 Aug;13(4): 343-403. doi: 10.1007/s10029009- 0529-7. Epub 2009 Jul 28.

12. Bittner, R. et al. Update of Guidelines on Laparoscopic (TAPP) and Endoscopic (TEP) Treatment of Inguinal Hernia (International Endohernia Society). Surgical Endoscopy. 2015; 29(2):289-321. DOI:10.1007/ s00464-014-3917-8.

13. Gilbert AI. A bilayer patch device for inguinal hernia repair. Hernia. 1999;3(3):161-66.

14. Faraj D, Ruurda JP, Olsman JG, van Geffen HJAA. Five-year results of inguinal hernia treatment with the 


\section{Original Research Article}

Prolene Hernia System in a regional training hospital. Hernia: the journal of hernias and abdominal wall surgery. 2009; 14.155-8.DOI 10.1007/s10029-009-0576-0.

15. Hawker GA, Mian S, Kendzerska T, French $M$. Measures of adult pain: Visual Analog Scale for Pain (VAS Pain), Numeric Rating Scale for Pain (NRS Pain), McGill Pain Questionnaire (MPQ), Short-Form McGill Pain Questionnaire (SF-MPQ), Chronic Pain Grade Scale (CPGS), Short Form-36 Bodily Pain Scale (SF-36 BPS), and Measure of Intermittent and Constant Osteoarthritis Pain (ICOAP). Arthritis Care Res (Hoboken). 2011 Nov; 63 Suppl 11:S240-52. doi: 10.1002/acr.20543.

16. Bernard Rosner. Fundamentals of Biostatistics, 5th Edition, Duxbury. 2000; page 80-240.

17. M. Venkataswamy Reddy. Statistics for Mental Health Care Research, NIMHANS publication, INDIA. 2002; page 108-144.

18. Sunder Rao P S S, Richard J. An Introduction to Biostatistics, A manual forstudents in health sciences, New Delhi: Prentice hall of India. 2006; 86-160.

19. Matyja A, et al. Assessment of inguinal hernia treatment results in patients operated on with mesh using Lichenstein, PHS and Robbins- Rutkow techniques. Videosurg Miniinvasive Tech. 2010;5:27-34.

20. Karaca AS, Ersoy OF, Ozkan N, Yerdel MA. Comparison of inguinal hernia repairs performed with Lichtenstein, Rutkow-Robbins, and gilbert double layer graft methods. Indian J Surg. 2015;77(1):28-33.DOI:10. 1007/s12262-013-0809-4
21. Badkur M, Garg N. Comparative Study of Prolene Hernia System and Lichtenstein Method for Open Inguinal Hernia Repair. J Clin Diagn Res 2015; 9 (6): PC04-7. DOI:10.7860/JCDR/2015/12177.6009.

22. Shankar JCR, Hiregoudar AD. Comparative Study between Lichenstein Mesh Repair and Prolene Hernia System in the Management of Uncomplicated Inguinal Hernia. IJSS Journal of Surgery 2016;2(5):5-11.

DOI: $10.17354 /$ SUR/2016/38

23. Gohel J, Patel U. Prolene hernia system in the tensionfree repair of primary inguinal hernias. Natl J Med Res 2012; 2(3):302-5.

24. Mottin CC, Ramos RJ, Ramos MJ. Using the Prolene Hernia System (PHS) for inguinal hernia repair. Rev Col Bras Cir. 2011 Jan-Feb;38(1):24-7.

25. Fitzgibbons RJ, Richards AT, Quinn TH. Open hernia repair. In: Wilmor DW, Fink MP, Jurkovich GJ, Kaiser LR, Pearce WH, Pemberton JH, et al., editors. ACS Surgery: Principles and Practice. 2nd ed. Ch. 21. New York: Webmed Inc.; 2003. p. 668-93.

26. Yener O, Aksoy F, Güzel P, Bölük S, Dag E, Atak T. Long-term quality of life after hernioplasty using a Prolene hernia system in adult inguinal hernia. Hernia 2012; 16 (1): 29-32. DOI: https://doi.org/10.1007/s10029011-0855-4

27. Pierides G, Vironen J. A prospective randomized clinical trial comparing the Prolene hernia system and the Lichenstein patch technique for inguinal hernia repair in long term: 2 and 5 year results. Am J Surg 2011; 202(2):188-93. DOI: http://dx.doi.org/10.1016/j. amjsurg. 2010.06.027.

\section{How to cite this article?}

Santosh M.P, Niyaz Mohamed S. Analysis of prolene hernia system in the management of uncomplicated inguinal hernia in comparison to lichtenstein mesh repair. Surgical Update: Int J surg Orthopedics. 2017;3 (4): 99-106.doi:10.17511/ijoso. 2017.i04.02. 